Viramin deficiencies lead to symptoms or disease. The two essential fartr acids relate to the integrity of cell membranes and to immunity. Linolenic acid is the predominant fatty acid in green leaves and fish. Linoleic acid comes from vegetable seeds, such as the sunflower.

Key metabolic functions apart, vitamins and trace elements combine to provide protection against chemical and oxygen toxicity. Antioxidants destroy damaging free radicals, and so prevent tissue damage, including the initiation of arteriosclerosis. The special role of vitamin C, vitamin E, carotene, and selenium as antioxidants indicates the importance of maintaining an optimum intake of vitamins and trace elements. The value of dietary fibre has been well recognised but it now seems that, apart from helping bowel function, it is the fibre-rich foods that are especially important sources of trace elements and vitamins. ${ }^{2}$

In maintaining health one does not need to know the names or chemistry of any essential nutrients but everyone ought to be aware of the groups of foods in which they are concentrated. Most people will know about vitamins $B$ and $C$ but all the other essential nutrients serve equally important roles. The need for trace elements is far better appreciated for horses, sheep, and pets than it seems to be for man. The micronutrients are concentrated in "whole" foods (eg, cereals and pulses) but so much is being taken away by refining processes, as in white flour. Some fresh leafy greens and fruit are also needed, to balance the losses of essential nutrients during cooking.

The Ministry of Food's campaign in the 1940s was accompanied by a fall in deaths at all ages to well below the pre-war trend. It has been generally assumed that this improvement in health was due to the lower consumption of fat and sugar and the elimination of overconsumption because of rationing, aided by the extra exercise from petrol scarcity. Another possible explanation has not received sufficient consideration. In those years the entire nation had a near-optimum intake of vitamins and other essential nutrients thanks to the universal use of the $85 \%$ extraction "national loaf" and a vigorous campaign on protective foods. Via leaflets for housewives, chats by the "radio doctor", cinema publicity, and booklets, all with a light touch, the whole nation soon understood the role of "body building and repairing", "energy giving", and "protective" foods. The leaflet for women ("health and beauty in war-time") would have been a credit to any successful advertising agency today. ${ }^{3}$

The wartime protective foods ensured a near-adequate supply of the six known vitamins, two trace elements, one essential fatty acid, and minerals. The fibre and extra trace elements, vitamins, and essential fatty acids we know about now would all have been present in those foods.

The campaign for healthy eating today focuses on saturated fat and cholesterol, about which the public remain confused-no wonder, since the experts are far from unanimous. Has not the time come to alter the priorities by making protective foods the prime objectuve, while still urging some reduction in fats? The promotion of protective foods has a firm scientific foundation; it would be uncontroversial and easy to understand; and the advice is positive "do", not "don' $t$ "). It carries the bonus that if these foods are taken there is nothing on the supermarket shelves that should not be eaten, in moderation. The protective foods (plus modest purposeful daily exercise and a weighing machine) may prove to be the essentials for physical well-being and strong defences against disease. It worked in the 1940s. We may have more variety today, with new flavours and novel culinary delights, but the nutritional principle is the same. Protective foods should be the first into the shopping basket, leaving less room for the domestically convenient but less healthy processed refined fast foods and even providing some counter to their possible baneful effects. So often there is a cycle of fifty years between discovery and rediscovery. Could this be another example?

3 House.

"itboume,

P. borough RH2O 2HE, UK

F. AVERy JONES

1 Parke DV The role of enzymes in protectron mechanisms for human health. Regul T.xicol Pharmacol 1987, 7:222-35.

:arres WPT. Duthe GG, Wahle KWJ The Mediterranean diet protective or simply son toxic' Eur 7 Cln Nutr 1989, 43 suppl 2: $31-11$

B.LA Report of the Committee on Nutrition 1950

\section{Anaphylaxis to glafenine}

SIR,-Anaphylaxis to glafenine has been documented, usually as case-reports. ${ }^{1-3}$ In the Netherlands, glafenine has been the most frequently reported cause of drug-induced anaphylaxis since its registration in 1967. In 1980-84, for instance, 121 cases of anaphylaxis to glafenine were reported to the Netherlands Centre for Monitoring of Adverse Reactions to Drugs. ${ }^{+}$Because data from voluntary reporting give no insight into frequency we studied the relative risk of severe anaphylaxis to glafenine on the basis of hospital diagnoses. The data, collected from all academic and general hospitals, were for all admissions during one year (1981) for which one or more of the following ICD diagnoses had been recorded: 995.0, 995.4, and 999.4 (anaphylaxis, shock due to anaesthesia, anaphylactic shock due to serum). Detailed clinical information was sought and an anaphylactic reaction was defined as any reaction within an hour after exposure to any cause and in which one or more of the following organ systems ${ }^{5}$ were involved:

Circulatory. Collapse or hypotension (systolic blood pressure

$<100 \mathrm{~mm} \mathrm{Hg}$ and symptoms compatible with hypotension).

Respiratory. Dyspnoea (eg, from laryngeal oedema or spasm or bronchospasm).

Skin. Urticaria, angio-oedema, erythematous rash.

Gastrointestinal system. Nausea, vomiting, diarrhoea, faecal urgency.

An anaphylactic reaction was considered "probable" if the symptoms met the above criteria, and if the reaction happened within $60 \mathrm{~min}$. Gastrointestinal symptoms as the sole clinical manifestation were not classified as anaphylaxis. Where circulatory failure was the single sign a case-history was classified as anaphylaxis only if cardiac causes had been excluded and if a vasovagal reaction was unlikely. An anaphylactic reaction was considered "possible" if the symptoms were consistent with anaphylaxis, and if the reaction occurred within $120 \mathrm{~min}$ or if the temporal relation was given as "immediate" or "shortly after administration". The risk of severe anaphylaxis to glafenine relative to indomethacin and to oral penicillins was estimated from the numbers of admissions attributed to glafenine and to indomethacin and pencillins and from reimbursement figures for these drugs, as supplied by the Association of Social Health Insurance Funds.

Clinical details were received for 136 of 166 admissions in 1981. Cases with scanty data were excluded from the analysis. In the remaining 120 cases, anaphylaxis was deemed probable in 90, possible in 17, and unlikely in 13. The 107 likely (probable or possible) cases of anaphylaxis concerned 46 men and 61 women, with a mean age of 47 (range $4-80 ;$ SD 18) and $48(9-80,19)$ years, respectively. In 56 cases anaphylaxis was the reason for admission; in 46 patients the reaction developed in an inpatient (22) or in the outpatient department (24); and in the other 5 the circumstances were not known. Recovery was complete in 102 patients; 2 patients died (cause attributed to dextran and contrast medium); in 3 the outcome was unknown. The following symptoms were mentioned in the discharge data: shock/hypotension in 79 (noted as absent in 13), dyspnoea in 34 (absent in 39), and skin reaction in 62 (absent in 16). $25 \%$ of patients had gastrointestinal symptoms. Drugs were the most common cause of anaphylaxis. The most frequently reported causes were glafenine (14) and contrast medium (28). A separate analysis of all cases of anaphylaxis as a reason for admission from outside the hospital showed that glafenine was implicated in $21 \%$ of admissions and accounted for $34 \%$ of drug-induced causes of admission. The risk of severe anaphylaxis to glafenine was estimated at $19 \cdot 3(95 \%$ confidence interval $4 \cdot 5-82 \cdot 3)$ for tablets/ capsules and $11.7(2 \cdot 4-58 \cdot 2)$ for prescriptions relative to indomethacin, and at $13 \cdot 4(2 \cdot 8-64 \cdot 1)$ and $20 \cdot 2(4 \cdot 8-84 \cdot 8)$, respectively, relative to oral penicillins.

Reporting bias could not have played a part because our analysis was based on all principal diagnoses from all Dutch hospitals. Recognition or referral bias seem unlikely because anaphylaxis is easily recognised in most cases and because there are no reasons to believe that glafenine-induced anaphylaxis is any different in severity from that seen with other drugs.

Clearly the risk of anaphylaxis to glafenine is high, and it is likely that these results apply to other countries as well. This risk should 
be taken into account when deciding whether or not to prescribe this analgesic.

Department of Internai Medicine II

University Hospital Dııkzigt,

3015GD Rotterdam, Netherlands;

Dutch Centre for Health Care Information,

Utrecht, and Netherlands Centre for Monitoring

of Adverse Reactions to Drugs, Rijswijk
B. H. CH. STRICKER

R. R. M. DE GROOT

J. H. P. WILSON
1. Meyboom RHB. Anafylaxis na het gebruik van glafenine. Ned Tijdschr Geneesk 1976; 120: $926-27$.

2. Machaud JL, Doublet L. Choc induit par la glafénine: six nouveau cas. Nouv Presse Méd 1976; 5: 716

3. Cheymol G, Biour $M$, Bruneel $M$, Albengres E, Hamel JD. Bilan d'un enquête nationale prospective sur les effets indésırables de la glafénine, de l'antrafénine et de la floctafénine Thérapie 1985; 40: 45-50.

4. Anon. Acute overgevoeligheidsreacties door geneesmiddelen. Bull Bijwerk Geneesmdd 1987; 3: 1-11.

5. Wasserman SI, Marquardt DL. Anaphylaxis. In: Middleton E, Reed CE, Ellis EF, Adkinson NF, Yunginger JW, eds. Allergy' principles and practice. 1988: 1365-76.

\section{Publicity and controversial data}

SIR,-I was shocked by Ms Tuffs' comment (Sept 1, p 558) that Prof Günther Harisch "is very unlike Benveniste, who publicised his results before any scientific discussion was possible". I published an article in the European fournal of Pharmacology in 1987, describing an ex-vivo immunological effect of homoeopathic dilutions of silica. Another paper appeared in the British fournal of Pharmacology in 1988, describing in-vitro effects of other homoeopathic drugs. In 1986 I submitted a paper to Nature that was published in June, 1988. Nobody can find any "publicity" by myself or my collaborators on the two first papers (both seem to have been forgotten by all participants in the controversy) and none before our Nature paper. Any publicity was started by Nature, which dealt with the paper in a spectacular way, including several press releases.

I did indeed comment on these very important results but only after publication. It has been a constant attitude of those who do not want to accept disturbing data to confuse deliberately the huge publicity for these data accorded by the world's press-indicating that the findings had pricked the imagination of journalists and lay people - with a systematic publicising attitude by me. Journalists ought to be able to understand the difference between articles on Benveniste's data and articles from Benveniste on his data.

Your Round the World correspondent writes "Benveniste never retracted his findings". Far from retracting my results I will (try to) publish in the months to come indisputable proof.

INSERM Unit 200,

University of Paris,

92140 Clamart, France

J. Benveniste

\section{Ascorbic-acid-induced haemolysis in G-6-PD deficiency}

SIR,-Patients with a deficiency of glucose-6-phosphate dehydrogenase (G-6-PD) are susceptible to haemolysis upon exposure to certain drugs, infections, or fava beans. ${ }^{1}$ Vitamin $\mathrm{C}$ (ascorbic acid) has been thought of as a safe drug when given in normal therapeutic doses to patients with G-6-PD deficiency, ${ }^{2}$ but there have been reports of haemolysis associated with large doses. ${ }^{3-5}$ We describe two patients with G-6-PD deficiency who presented with severe haemolysis after consumption of large quantities of soft drinks containing ascorbic acid.

A 10-year-old boy was admitted to hospital in a stuporose condition with a history of passage of cola-coloured urine for a day He was very pale and icteric, with tachypnoea and tachycardia. His blood pressure was $90 / 50 \mathrm{~mm} \mathrm{Hg}$. He was incontinent of cola-coloured urine. He was given 3 units of packed cells. The next morning, he was comfortable and fully oriented, but still pale. The haemoglobinuria persisted for 4 more days, and he required 3 more units of packed cells. His lowest haemoglobin was $3 \mathrm{~g} / \mathrm{dl}$. His peak reticulocyte count was $45 \%$ and he was erythrocyte G-6-PD deficient even at peak reticulocyte count. His serum bilinubin was $9 \mathrm{mg} / \mathrm{dl}$ (indirect 7.5).

On the day after the admission of this boy, his cousin was brought: in with similar but less severe complaints. His haemoglobinuria persisted for 3 days, and he was not transfused. Investigations were: haemoglobin (lowest) $5 \mathrm{~g} / \mathrm{dl}$, reticulocytes (peak) $27 \%$, erythrocte G-6-PD (at peak reticulocytosis) deficient, serum bilrubr. $7 \cdot 2 \mathrm{mg} / \mathrm{dl}$ (indirect $6 \cdot 2$ ).

Subsequently, the mothers of both boys were found to have diminished G-6-PD activity. Neither boy had a history of drug or fava bean ingestion and there were no symptoms or signs of infection. Neither was known to have G-6-PD deficiency, and there was no history of haemolysis. Further inquiry revealed that the boys, who had lately returned from a boarding school for the summer holidays, had gone on a soft drink binge and consumed 8-10 helpings of 'Tang' (General Foods, USA) and 2-3 glasses of a lemon-flavoured soft drink over $4-6$ hours. Tang contains about ij $\mathrm{mg}$ vitamin $\mathrm{C}$ per helping and the ascorbic acid content of the lemon drink was $1000 \mathrm{mg}$ per $200 \mathrm{ml}$ glass. The boys had thus consumed $3-4 \mathrm{~g}$ vitamin $\mathrm{C}$ each in $4-6$ hours.

Winterbourn ${ }^{6}$ found that ascorbate could substitute for reduced glutathione and act as a scavenger for toxic oxygen radicals, protecting G-6-PD deficient red cells against oxidant stress. However, serum ascorbate levels above $5 \mathrm{mmol} / \mathrm{l}$ could cause oxidative haemoglobin breakdown and haemolysis. The protective range was $0 \cdot 1-1 \mathrm{mmol} / 1$ (normal $0 \cdot 03-0 \cdot 08$ ). Beutler noted a fall in the reduced glutathione levels when G-6-PD deficient red cells were incubated with high levels of vitamin $\mathrm{C}$. Brewer et al ${ }^{4}$ noted mild haemolysis in G-6-PD deficient individuals given $15 \mathrm{~g}$ vitamin C orally.

It is almost certain that the haemolysis in these two boys was caused by the soft-drink consumption. It is very unlikely that consumption of normal amounts of ascorbate-containing drinks would have such serious consequences. The boys are currently well-on a strictly rationed soft-drink diet.

JAYESH B. MEHTA

Blood Research Centre Seema B. Singhal. Bombay 400058 , India Bhupatrai C. MeHTA

1. Mentzer WC, Glader BE. Disorders of erythrocyte metabolism In Mentzer W'C Wagner GM, eds. The hereditary hemolytic anemias. New York Churchil Livingstone, 1989: 288-92.

2. Beutler E. Hemolytic anemia in disorders of red cell metabolism. New York. Plenum. 1978

3. Udomratn $T$, Stemberg MH, Campbell GD, Oelshlegal FJ Effects of ascorbic add on glucose-6-phosphate dehydrogenase-deficient erythrocytes: studies on an anuma! model. Blood 1977; 49: 471-75.

4. Brewer GJ, Tarlov AR, Alving AS. Standardization of procedures for the studr of glucose-6-phosphate dehydrogenase. WWHO Tech Rep Ser 1967, no 366.

5. Campbell GD, Steinberg MH, Bower JD. Ascorbic acid-induced hemolssis in G-6-PD deficiency. Ann Intern Med 1975; 82: 810 .

6. Winterbourn CC. Protection by ascorbate against acetylphenyl-hydrazne-nduad Heinz body formation in glucose-6-phosphate dehydrogenase deficum erythrocytes. Br f Haematol 1979; 41: 245-52.

7. Beutler E. The hemolytic effects of primaquine and related compounds a terte Blood 1959; 14: 103-38.

\section{Infectious aetiology of childhood leukaemia}

SIR,-Dr Kinlen and his colleagues (Sept 18, p 577) interpret ther results as implicating some specific infectious agent but agree that much of their data could be interpreted in terms of the pattem of non-specific infections, according to Greaves' hypothesis. ${ }^{1}$

Our findings ${ }^{2}$ relate acute lymphoblastic leukaemia (ALL incidence, especially in the childhood peak age range (1-7 years if community isolation rather than population mixing. They suppor an infectious aetiology for ALL but tend to favour the Greale model. To distinguish the two hypotheses unambiguously wht epidemiological data is difficult, and the debate is likely to contunue

Meanwhile the alteration in the shape of the age-spetrif mortality curve in the rural new towns, evidenced by excesses: ages $0-4$ and deficits amongst other young people, is of speriz interest. Analysis of data from an atlas of leukaemia and lymphom. incidence for twenty-two counties of England and Wales in $1984-88^{3}$ reveals a surprising lack of association (even a weas 